\title{
Systemic Properties of Judgmental Discourse
}

\author{
Alexandra V. Radyuk ${ }^{1} \&$ Marina V. Kuznetsova ${ }^{1}$ \\ ${ }^{1}$ Peoples' Friendship University of Russia (RUDN University), Moscow, Russia \\ Correspondence: Alexandra Radyuk, Assistant Professor of Foreign Languages Department, Faculty of \\ Economics, Peoples' Friendship University of Russia (RUDN University), 117198, Miklukho-Maklaya str. 6, \\ Moscow, Russia. E-mail: radyuk-av@rudn.ru
}

Received: August 6, 2020

Accepted: September 11, 2020

Online Published: September 15, 2020

doi:10.5539/ijel.v10n6p224

URL: https://doi.org/10.5539/ijel.v10n6p224

\begin{abstract}
The article is devoted to an acute and insufficiently studied issue - the issue of judgmental discourse. While the business language is considered clichéd and neutral, the cases of direct expression of attitude are attracting more attention nowadays. The article attempts to find out what functions judgmental discourse in general performs, as well as what the role and the functional load of a positive assessment is.

The material for the study covers excerpts from the business press with examples of positive assessment. The study was carried out using methods of analysis and synthesis, classification, functional-synergetic analysis served as a private scientific method.

The article shows that the perception of discourse is a complex phenomenon, subject to the laws of cognition. A language built linearly acquires multidimensional shades of meaning, being actualised in discourse. Consideration of discourse as a synergistic system of meanings highlights properties uncharacteristic for a linear system. For example, the communicative goal can be achieved through undertaking unexpected speech turns, and the use of implications can increase the rhetorical efficiency of an utterance.

The author analyses the three most common speech tactics used in judgmental discourse-praise, compliment/flattery, self-identification - and on their material describes synergistic properties - systemacy, openness, self-organisation, non-linearity and heterogeneity of the semantic system of discourse.

The study has shown that a positive assessment in the structure of judgmental discourse is widespread and is realised at various levels of the discourse system. In publicistic business discourse, judgment is used not just to express an attitude; it is a tool for forming an opinion, creating a certain image, expressing the position of a printed medium.
\end{abstract}

Keywords: functional linguistics, linguosynergetics, judgment, assessment, discursive strategies, discourse system, evolution, non-linearity

\section{Introduction}

\subsection{Introduction to the Problem}

The English language has become global due to the internationalisation of business activities and the constant growth of business contacts. In this regard, certain targets and models of speech behaviour with specific features have been developed for the English business discourse (see, for example, Malyuga \& Orlova, 2016; Malyuga et al., 2016; Malyuga et al., 2019; Ponomarenko et al., 2020). However, there can be observed a new trend of incorporating the techniques and means that were not previously characteristic for this type of discourse in business English. This affects the perception of business discourse, especially in print and electronic press. We evidence that it has become more categorical and opinionated. Communicants strive to stress the importance of their expertise and impose a particular vision of facts and state of affairs. That is why we have called judgmental discourse the object of our research. Particularly, we intend to study the judgmental side of positive assessment in the sphere of business English pragmatics.

This study has been carried out on the material of quality business press. On the one hand, it is an attempt to identify and describe the pragmatic impact of the media on the reading audience through the usage of particular pragmatic tools - evaluative speech tactics and strategies. On the other hand, it is a description of the systemic nature of judgmental discourse. Language material encompasses the business-related articles published in the 
Economist, the Wall Street Journal, BBC Business, the Guardian, Harvard Business Review for 2019-2020.

\subsection{Importance of the Problem}

Effectuation of pragmatic impact is one of the characteristics of the media, as all the media attention is paid to the person and the activities implemented by people. Pragmatic analysis of media texts should answer how the media displays all the events and how the methods of influence in mass communication work. Appeal to the field of mass media in the study is relevant from the point of view that at the present stage of social development the media is the main environment in which the most important acts of communication for society and the individuals take place (Georgakopoulou, 2002).

The object of study in the article is speech strategies and tactics which are aimed at forming judgment about various business, social, and political phenomena.

We saw our objective in analysing discursive strategies and tactics of positive assessment in English newspaper business texts to find out the most productive ones and describe their influence on the audience.

According to this objective, the following tasks are carried out:

1) to give a taxonomy of the most frequent tactics realising strategies of positive assessment used in newspaper business texts;

2) to examine the ways speech strategies and tactics used in newspaper business texts influence the readers' perception of facts;

3) to explain the functional and systemic nature of assessment in judgmental discourse.

\subsection{Relevant Scholarship}

In modern linguistic science, researchers have been paying attention to speech tactics and strategies which are used to implement communicative intentions for several decades (Fr. Bargiela-Chiappini, T. A. van Dijk, A. Georgakopoulou, M. A. K. Halliday, C. Matthiessen, O. S. Issers, P. B. Parshin, N. D. Arutyunova, T. N. Astafurova, A. N. Baranov, E. N. Zaretskaya, V. I. Karasik, R. Kilmann, N. N. Mironova, E. N. Malyuga, I. A. Sternin, N. I. Formanovskaya). Pragmatic impact of mass media speech has attracted the attention of researchers in semantics, stylistics, rhetorics, psychology, but still there have been no descriptions of a systemic nature of assessment on the material of business discourse.

We rely on T. van Dijk's concept of discourse, according to which discourse is "an essential component of sociocultural interaction, the characteristic features of which are interests, goals, and styles" (Dijk, 2000, p. 53). On the one hand, it is a complex communicative event that occurs between the speaker and the listener in specific temporal, spatial, and other contexts. On the other hand, discourse is understood as an oral or written text, represented only by a verbal component. Based on these understandings, discourse is a complete or continuing "product" of communicative action, its written or oral result, which is interpreted by the recipients.

In the functional paradigm, the principles of language usage in society are considered both from the point of view of pragmatic approaches to discourse and taking into account certain social factors (gender, age, profession, opinions of speakers, etc.). The emphasis is also placed on intentions, emotions of the speakers.

Business discourse has some distinctive features. As noted by T. A. Shiryaeva, the main one is the specific goal of communication - mutually beneficial professional activity, establishing conditions for cooperation, achieving a business agreement (Shiryaeva, 2018).

The users of business discourse are people who are professionally involved in doing business, managers of different levels responsible for production, trade, and service provision; business people who own their businesses; as well as scientists engaged in scientific research; specialists who provide consulting and expert services; as well as specialists from other fields in formal business situations (Mak, 2019).

In business discourse as a communicative event, the action is set in social space and time, which are important elements for social relationships with communicants (Chan \& Du-Babcock, 2019).

Such relationships are maintained under the influence of specific values - making a profit, effective management, creating partnerships, surviving in a competitive environment, finding qualified personnel, etc. (Shiryaeva, 2018).

The registers of business discourse and the corresponding discursive strategies and tactics are distinguished (depending on the purpose of professional communication, means of communication, they are most often classified into a presentation, negotiations, articles in special media, interviews, training) (Ponomarenko et al., 2020). The combination of these registers forms a special picture of the world, characterised by the conditions 
for the existence of the business community (Bargiela-Chiappini et al., 2007).

It is necessary to state that the notion of a speech strategy has gained a shared understanding but is expressed in various definitions. According to T. A. van Dijk, the strategy is a property of cognitive plans, and it is a general organisation of some sequence of actions and includes the goals of interaction (Dijk, 1983). In such a way from the perspective of this definition, a common vector of speech interaction is established in the process of strategy development. According to T. A. van Dijk, the achievement of a goal is one of the qualities of an appropriate strategy following the desires and preferences based on the "action plan".

According to E. V. Zhdanova, speech strategy is "a consciously chosen general line of behaviour used by the speaker to realise his global communicative goal, which is to correct the model of the interlocutor's world" (Zdanova, 2010, p. 45).

Also, there is another definition given by O. S. Issers. The speech strategy is a product of speech planning because "it includes the process of the planning of the communicative act according to the specific conditions of this act and the person and also the implementation of this plan" (Issers, 2012, p. 54). Cognitive processes constitute the speech strategy and precede the verbal stage of speech actualisation. Herein lies an important quality of flexibility - arranging the concepts and scenarios the speaker may adapt the speech correspondingly in the context of the conversation.

In respect of linguosynergetics, discursive strategy is a direction of discourse evolution (Radyuk, 2013, p. 6). It is forwarded to mutual influence and forms the discourse system where functional augmentations appear. These augmentations synthesise and modify the initial pragma-semantic components of discourse.

Because in nowadays world the development of the media has given access to information through newspapers, magazines, television, radio, and the Internet, evaluative statements presented in the media are an effective means of influencing readers. Thus, pragmatic influence is the main tool for achieving goals in the English business media discourse. The control of its intensity to a greater or lesser extent allows to modify the direction of the semantic system to the desired extent and to achieve the influence corresponding communicative purpose (Radyuk, 2013).

\subsection{Research Hypothesis}

At the beginning of our work, we suggested that one of the most important functions of business discourse is the pragmatic one. According to this function, the speech means are arranged unconsciously and consciously by the speaker to accumulate the pragmatic potentials of separate levels (lexical, syntactic, stylistic, phonetic) (primary hypothesis).

The secondary hypothesis was that the pragmatic impact can be effectuated by several discursive strategies and tactics; that the system of discourse is undergoing evolutionary processes and judgment is a component of the external environment of discourse (in linguosynergetic sense) influencing the final speech impact.

\section{Method}

Apart from common scientific methods, the main method was discourse analysis and functional synergetic analysis. Combining these two methods, we managed to identify and classify the strategies of positive and negative assessment as well as track their systemic properties, i.e., the properties of systemacy, openness, self-organisation, non-linearity, and heterogeneity. Seeing samples of business discourse as synergistic systems of verbal means of expression, and following the model of linguosynergetic analysis (Ponomarenko, 2016), we explain the evolution process of pragma-semantic systems of judgmental discourse.

Analysing discourse as an open nonlinear self-organizing system, the linguosynergetic method considers the pragma-semantic relations between utterances (Ponomarenko, 2018). When considering a separate speech sample, it is viewed as a system (an ordered object that exists in the external environment according to the laws of self-organisation). Its elements function inside the system. In the case of discourse, it is guided by the global intention of the author (functional attractor) - the area of attraction of the pragmatic potential of multi-level speech tools. For example, a functional attractor in negotiations with foreign partners is concluding a mutually beneficial deal. The speech tools chosen by the speaker (pressure strategy, flattery tactic, threats, appeals, the use of direct address, imperatives, the use of high intonation), and extralinguistic factors (non-verbal signals) are elements of this system aimed at concluding a deal. Judgment (specific attitude) is also a component of the outer environment of the discourse system.

It is important that the system is constantly undergoing internal changes (speech behavior is corrected, the interlocutors make concessions), and external influence. The source of external fluctuations can be the 
consciousness of communicants, the communicative situation (for example, the transfer of negotiations to the premises of the counterparty).

\section{Judgment in the Pragmatic Space of Business Discourse}

Judgmental discourse is a communicative event imposing the particular vision of facts. Judgment is effected by using particular discursive strategies that form a positive or a negative attitude towards various business phenomena (Frana \& Rawlins, 2019). The strategy of speech behaviour covers the entire construction of the communication process when the goal is achieving certain long-term results.

Generally, assessment strategies are used to present facts with attribution of positive or negative characteristics to phenomena occurring in the social, economic, and political spheres (Chatti, 2020). It should be noted that the presentation and evaluation of the facts also include two components: the author's position and the ideological position of the printed source. Presenting information lying in the sphere of public relations, mass media uses such means as title and headlines, theme, lexical units, metaphors, colouring or perspective, and many other semiotic characteristics of discourse.

Assessment strategies as a part of judgmental discourse are widely used by journalists in media worldwide in covering all political, social, and economic spheres because evaluation is an indispensable part of human nature. Judgment and evaluation become tools constructing the images of states, parties, companies, and businessmen (Hamiti \& Sadiku, 2020).

On the one hand, the researchers note that personal opinion and personal assessment are connected with the journalists' desire for self-expression in the media discourse. According to N. A. Bankovskaya, the journalist not only aims at the statement of information and the presentation of the newspaper but at showing the world through the prism of his or her own "self" to the reader (Bankovskaya, 2007, p. 110). The author's assessment has a direct impact on the perception of the readers. The researcher says that the more talented a journalist is, the closer the author's position to the reader, and the better such assessment is perceived (Ibid., p. 111). On the other hand, the essence and content of the assessments are determined by the ideological position of the printed edition, which has a direct impact not only on the representation of certain events but also on the selection of facts chosen for coverage.

According to E. M. Volf, there is a subject and an object of the assessment. The subject of assessment structure is understood as a person, a part of society or society as a whole, from which point of view the assessment is made (Volf, 2006, p. 68). Moreover, the researcher singles out the following forms of the subject:

- a certain person (personal assessment);

Looking back, I would rather have Britain's 1832 - and 2016 - than France's 1792 or Germany's 1933 (The Guardian, 2020).

In that case, we understand that the author presents his point of view using the personal pronoun ' $I$ '.

Is this fair? Is this discriminatory? Is this anti-business? Oh please. To me, the law doesn't go far enough (The Guardian, 2020).

Here we can note how the objective form of a pronoun can be presented as a subject of assessment.

- "generalised" subject;

Although the idea of people being fed abhorrent rhetoric and conspiracy theories is nothing new, what we have seen in the past decade is an absolute explosion in the ready availability of this content, and easy access to the networks behind them (The Guardian, 2020).

This example illustrates that the author tries to get closer to the reader, presenting not his own evaluation, but giving an assessment using the pronoun 'we'.

- the assessment presented as having no subject and veritable in the "real world"-in that case, the basis of the assessment is the conceptual world of the speaker (Volf, 2006, p. 69).

Today the company, TD Tom Davies, makes 50,000 pairs of glasses a year, and has a host of celebrity customers including singer Ed Sheeran, chef Heston Blumenthal and Hollywood actress Angelina Jolie. Not a bad state of affairs for a former art student from the East Midlands city of Derby who never actually intended to become a glasses designer (BBC Business, 2020).

This example shows the expression of an assessment based on the previous description of the facts, so there is no subject of assessment and it is presented as a conclusion on a certain issue. 
The object of assessment is understood as a person, an object, an event, or a state of things to which the assessment relates.

It is evident that the subject and the object, as well as the reader and the author, are in the same time continuum and in the same conditions that are common to them. In that case, assessment not only performs the function of persuasion but also from the perspective of cognitive science can discover new knowledge. Therefore, the reader, perceiving the assessment of the subjects about the objects, can:

- bring out new information both about subjects and objects of assessment and about the variety of relations between them;

- form his own judgment about the new information, decide what to accept and what to reject (Frolova, 2015, p. 98).

When the author chooses an object for assessment, the fundamental criterion is the unity of importance, the significance of the event, and its moral value. It means that in the study of the object of assessment the thematic and quantitative components of the object should be taken into account (Ibid.).

A. A. Ivin identifies the third component of assessment and calls it the basis of assessment. It includes the parameters from the point of view of which the assessment is made (Ivin, 2015, pp. 21-28). Taking into account all these components allows to systematise the speech strategies and tactics and to take into account their role and importance in the formation of assessment semantics.

Nowadays linguists distinguish the following properties of the evaluative judgment:

- emotiveness;

- emotionality and rationality;

- expressiveness;

- affectivity;

- intensification, i.e. strengthening of the sign "good" or "bad" (Gabidullina, 2013, p. 41).

Speech strategy implementation requires special techniques - speech tactics. They are special speech techniques that allow to achieve certain goals in a particular situation. It is known that in each sphere of communication certain tactics, which are specific for each case, prevail, for example, tactics of social communication or tactics of the business sphere. But this fact does not exclude the interpenetration of tactics of different levels with a certain modification. One tactic may be used to implement various strategies (Radyuk, 2013).

It should be remembered that in the business environment there are some rules that guide speech in the necessary direction. Accordingly, it is referred to the etiquette and generally accepted norms of speech behaviour. Speech tactics that are used for the implementation of strategies are not an exception. Usually, neutral stylistic devices are used in business discourse. However, sometimes specific figures of speech and expressions which can be regarded as impartial and offensive are used in journalism.

For realisation of assessment strategies, the tactics can be shared into various communicative turns. A communicative turn is the minimal pragmatic unit singled out by linguists. The pragma-semantic system of business discourse is developing on all language levels. The grammatical implementation of assessment tactics can be expressed by means of comparative and superlative forms of adjectives, imperative verbs, passive voice, etc. Lexical means of assessment can be represented by vocabulary with negative or positive semantics, the usage of set expressions, etc. Tactics involved in assessment can be based on the use of stylistic techniques such as irony, metaphor, epithet, etc. (Partington, 2007).

We studied assessment strategies and tactics used in articles and found out that in the business printed discourse the focus of each article is predetermined by its major and minor goals and objectives. Apparently, several different strategies can be used simultaneously in one article, for example, the basic one, which contains the main idea, the main communication appeal, and the auxiliary one, which introduces an additional assessment with the help of less significant factors. The flexibility of the language system allows speakers to adapt the means of speech influence and use their potentials synergistically - here the discourse system provides semantic augmentations, which lay the basis for implicitness, polysemy, hints, etc. Implicit assessment may have even a larger potential for persuasion than direct means (Jiang \& Zhang, 2020).

During the analysis of assessment strategies, two groups of strategies are identified: the strategies of positive assessment and the strategies of negative assessment. For the implementation of the strategies of positive assessment the tactic of praise, the tactic of flattery, the tactic of compliment, and the tactic of self-identification 
are used.

182 articles related to the business in such magazines as the Economist, the Financial Times, BBC Business, and the Guardian were studied. It is important to note that most often in each article several speech tactics were found. Further, we will analyse the ways of their pragmatic influence of the abovementioned means on judgmental discourse.

\section{Discussion}

\subsection{Strategies of Positive Assessment}

It is well known that mass media requires high rhetorical skill, which is expressed in the freedom to combine a variety of rhetorical techniques, communication strategies, and tactics. To be communicatively successful, the author should aim at an external target audience in order to expand the sphere of his influence, to make the audience believe him, at least, to follow his point of view.

Concerning the positive assessment strategies, it should be noted that the purpose of speech influence is a certain organisation of human activity in the right direction for the speaker, i.e., to create a positive image of the object described. Speech influence produces a shift in the value system of the recipient, in other words, reorients the consciousness of the participant of speech influence in order to inspire the reader that the described event has a positive result.

Positive assessment strategies can be considered as a kind of discursive strategy of persuasion. That is why when using this strategy, the authors often use quotations and statistics. This kind of information helps journalists to support their point of view with official data and statements of well-known influential people and makes the news more convincing for readers.

Evidently, assessment can be characterised as an element of persuasion strategy. This method of speech influence is realised with the help of argumentation. However, a statement can only be accepted as an argument when it is presented as a reasoned assessment. Therefore, cause-and-effect links are built between the parts of argumentative statements (Macagno \& Botelho, 2020).

Further, we will consider the particular tactics which correspond to positive assessment strategies.

\subsection{The Tactic of Praise}

The addressees of positive-evaluative statements experience a positive emotional charge, which they want to share with the interlocutor, to provide a positive emotional background of communication, to set the interlocutor on a harmonious communication. Positive assessment performs the psychological effect of support. Strategies of expressing a positive assessment produce an impact on the emotional state of the interlocutor, especially the tactic of praise, and are used by the addressees both in the case of the focus of praise on the interlocutor himself and in the case of praise to a third party.

Also, praise directed to a third party is characterised by the sincerity of the speaker, motivated by a desire to share a positive emotional experience: the speaker praises someone as an example to follow. A positive emotional charge of a particularly high degree of intensity is distinguished with the statement of praise if it is combined with gratitude.

In our study, where we discuss the journalistic sphere of business news, the object of praise will be just the third party, by which we mean the described object of the positive assessment strategy (event, figure, law, etc.).

Let us consider what verbal means can be used to realise the tactic of praise.

In the following excerpt the metaphor "keep eyes away" demonstrates, on the one hand, the function of praise, and the non-linear nature of discourse, on the other.

Given the extraordinary stats that show no fewer than 370,000 children aged 11 to 16 gamble each week - with 25,000 of those classed as problem gamblers - surely any move to keep young eyes away from temptation is to be applauded (The Guardian, 2020).

Using this metaphor, the author assesses the situation as very negative and tries to attract readers' attention to the horrifying statistics. Using the phrase "young eyes" the author means children and teenagers who are tempted to gamble after watching ads.

The property of non-linearity of discourse is manifested when the system, in the course of interaction of elements, reveals the properties of the whole. In the above example, the functional attractor is convincing readers that advertising restriction is an ineffective method of dealing with adolescent gambling. Throughout the article, the author repeatedly leverages the semantic dominant of the article - the word bet, often not referring to the 
actual process of betting on sports events. The fact is that it is part of various set expressions and idioms.

So, at the beginning of the article, "It's a fair bet" is used in the meaning of accurate planning of support for advertising restrictions. At the end of the article, we meet "You can bet on it" in the sense- "I bet that gambling will continue to exist". This wordplay creates an effect of surprise because the reader first of all perceives the direct meaning of the word bet (place a stake on something). The appearance of the lexeme bet can be called spontaneous, but its use serves as a more convincing argumentation tool of the author.

These spontaneous (emergent) properties are inherent in the discourse system as a whole and do not come from the meanings of separate words. On the way of evolution of the semantic system to a functional attractor, spontaneous fluctuations caused by the use of the polysemic word bet is bringing the discourse system into a state of relative chaotisation. Under the influence of order parameters, the elements of the system (propositions connected by pragma-semantic relations) self-organise and bring the system to a new level of equilibrium. The author sums up his arguments and brings the reader to the conclusion.

Idioms, such as "to keep young eyes away from temptation", have a similar non-linear property, whose meaning has nothing to do with individual constituents (eyes, retention), but is complemented by semantic augments (keep away - to restrict, temptation — gambling).

To implement the tactic of praise it is necessary to mention the usage of words with positive semantics among the lexical means.

Second, the west coast big tech companies, from Facebook to Apple, are the new wonders of the universe. They are the bewilderingly successful face of the informational, data-driven economy whose value continues to soar (The Guardian, 2020).

With the help of these words with positive semantics, the author creates a picture of two influential companies. It should be noted, the article is about the issue of the technological and financial condition of the two powers (the USA and China), with the help of a positive description of the companies representing America, the author emphasises the arguments against the United States as if assuming that this state has an advantage over China in the field of economy and technological development.

In the following example, the use of colloquialisms creates the image of support and praise.

It's a fair bet that the new rules announced today aimed at preventing the gambling industry from targeting children will be welcomed by almost everyone (The Guardian, 2019).

The author emphasises that it is impossible to remain indifferent to such an important issue as advertising gambling. Here the colloquialism also helps the author to create the effect that the reader is perceived not just as the recipient of information, but as a colleague and a friend of the author, with whom he can share his personal opinion using an informal style of speech.

It should be noted that from a grammatical point of view the authors often use the present continuous forms in the tactics of praise.

But the industry is now working hard to change that perception, and they're making the career accessible to absolutely everybody (BBC Business, 2020).

This article describes the story of a woman who wanted to become a pilot. But in connection with the established norm that the pilot should be a man, she hardly believed in her dream. However, now this profession has become available to all. Thus, the use of this tense emphasises that these positive changes are taking place right now. In this regard, the author expresses his praise for the air industry, which now is paying more attention to the pilot's abilities rather than the gender.

Considering the grammatical ways of implementing the tactic of praise, it is necessary to note the usage of gerund:

Putting growth before profits also suited its mighty unions, for which preserving jobs is paramount (The Economist, 2020).

In this case, the author gives a positive assessment of the activities of Volkswagen under the new management. With the help of the gerund, the author highlights the priorities of the company among which the primacy of the company's development over profit, also the author emphasises the good desire of the company to preserve jobs. Praise of this kind for the organisation creates a good image of the company for the audience. Thus, we can say that the pragmatic impact with the help of a gerund, in this case, is aimed at creating a positive image of the company in order to attract trust and customers. 


\subsection{The Tactic of Compliment/Flattery}

According to the studies in the sphere of sociolinguistics, psycholinguistics, communicative linguistics and pragmatics, it can be concluded that the compliment is used in primary and secondary social relations on different communication distances for intimidation of communication and self-identification of speakers in the construction of a dialogue of cooperation. The tactic of compliment implements a powerpoint in the communication and it is characterised by the variability of communicative ways and lexico-grammatical resources. In oral communication it demonstrates the sincerity of the interlocutors.

In mass media discourse compliment can also be used as a tactic to express the key strategies of positive assessment and emotional impact. The degree of emotional intensity is determined by the degree of sincerity of the author.

A compliment is understood as a positive-evaluative speech act that is characterised primarily by the coincidence of the target and the object of positive-evaluative statements (Bigunova, 2019). It is also characterised by a small expected exaggeration of the merits of the interlocutor. The compliment is formulated mainly within the framework of the initiating communicative course and differs from other positive-evaluative speech acts by the absence of argumentativeness in its communicative structure. The compliment is more often addressed to the communicant of equal status, less often it is addressed to the lower communicant.

The compliment tactic fully reflects the systemic properties of judgemental discourse. So, the property of heterogeneity is expressed in the appearance of spontaneous properties of the semantic system of discourse, fluctuations that are not characteristic of the initially given direction of evolution.

The following excerpt describes the problems of EU budgeting.

The European Union is a global heavyweight in trade and climate. But in political terms, it is puny. For all the Brexit conspiracy theories of a "United States of Europe", the EU has no federal government. Brussels is not the continent's capital, but home to its bureaucracy. The club's power lies with member states that zealously guard their interests and scrupulously defend their sovereignty. They often recoil from shared burdens and a collective will (Jenkins, 2019).

The beginning of the article is accompanied by a positive assessment of the EU as an economic union (global heavyweight in trade and climate). However, further, the author describes its failure as a political force. The use of a compliment tactic in the initial position makes the reader perceive this proposition as a starting point around which the author's further argumentation will be built.

However, the subsequent tactic of criticism (it is puny) creates dissonance, introducing relative fluctuations in the functional space of discourse - as it turns out, the real purpose of the message is to describe the contradictions in the EU budget policy.

Thus, the functional-pragmatic potential of the system elements is directed towards one functional attractor, but the tactic of compliment does not correspond to the movement towards this attractor.

How are such processes explained in linguosynergetics? Spontaneous fluctuations are quite natural for any open non-equilibrium synergistic system, including the discursive one. The functional potential of speech means that implement this tactic, in fact, runs counter to the direction of evolution of the system. In such cases, it has two paths of development: either to rebuild under the influence of the external factors or subordinate the chaotic element to its movement.

In this case, the second path occurs, and the aforementioned example enhances the influencing potential of speech means, creating an obstacle at the cognitive level, and forcing the reader to constantly return to the proposition "EU is a heavyweight" within the first paragraph and compare it with further critical arguments.

These fluctuations do not prevent the system from evolving, the communicative goal at the end of the article has been achieved, and the pragmatic effect of this rhetorical technique increases compared to the fact if the arguments were presented sequentially-linearly.

The tactic of compliment can be implemented using vocabulary with positive semantic meaning.

Today, it is one of the world's top outsourcing destinations, with many of its workers powering back-end IT systems, call centres and software development (BBC Business, 2020).

This example demonstrates an indirect compliment to Indian politician Narendra Modi. In the article, the author emphasises that under his leadership the country has achieved such high results in the field of outsourcing. A number of words with a positive semantic meaning convince the reader to believe that under the leadership of 
such a person, the country will achieve very great results, despite the fact that India was previously considered as one of the poorest countries.

Another way to implement a compliment tactic is to use the form of superlative adjectives:

Another carrier that is working hard to get more female pilots is Virgin Australia. It has set itself one of the toughest targets for new recruits-aiming to have a 50:50 gender balance for its cadet pilots (BBC Business, 2020).

In this case, the compliment is addressed to a particular air carrier Virgin Australia. Using this grammatical form, the author emphasises that this carrier is not afraid to set the most difficult tasks and fights for the equality of women in the profession. When reading this news, readers may perceive at a subconscious level that this company is not only the fairest to women but also the most qualitative, as all attention is focused on the superlative form.

Moreover, the following example with the usage of the comparative degree of the adjective illustrates this tactic.

But the evidence also suggests that employees work harder when they have quicker access to their money (The Economist, 2020).

In this statement, the author evaluates the work of employees by comparing the quality of their activities and possible access to money. The article touches upon the problem that not everyone can afford to pay everything from salary to salary. As a result, it was developed an application that provides monthly opportunity to take the necessary amount of money to pay for the essential goods. Thus, having access to money, work becomes more qualitative. The two adjectives used in the utterance seem to create a single logical chain of quicker access to money and harder work. The pragmatic orientation of this statement focuses on the employers. For them, this information can be useful for the purpose of developing their own similar applications for employees.

The following example shows the implementation of the tactic of compliment using grammatical mean, namely, the modal verb.

Dimon should know. He was at the helm when JPMorgan received a \$25bn socialist-like bailout in 2008, after it and other Wall Street banks almost tanked because of their reckless loans (The Guardian, 2020).

This example demonstrates the tactic of complimenting the CEO of JPMorgan Chase. In this case, the author reinforces his compliment with arguments, referring to the fact that this person already has the experience of bringing the company out of a difficult situation. In this case, the argument for the previous compliment also has a pragmatic impact on the reader. Referring to the previous success, the author gives the reader to understand that this person can be trusted. Consequently, readers begin to treat the man with great confidence.

The implementation of the compliment tactic is possible with the help of such a stylistic device as detachment.

Some carriers, such as Air France, however, cover the cost of training new pilots (BBC Business, 2020).

As the compliment is always directed to any object (person, company, etc.), it is necessary to select this object. In this case, this object is a certain airline. The reason for this compliment is the fact that this company takes a part of the cost of pilots' training to itself. The author underlines this company with the help of a stylistic device detachment to emphasise its positive sides for readers and create a good image of the company.

The tactic of compliment can also be implemented by such means as the opposition.

They do not want to mass produce commercial wines, and they don't work with large chains and supermarket. ... Instead they work with niche wine boutiques and high quality restaurants (BBC Business, 2020).

In this case, the opposition is based on the goals of Georgian companies engaged in winemaking. The author draws the attention of the readers to the fact that these companies do not set themselves the main goal of making a profit from the sales of wine. He emphasises that the company's activities are aimed at achieving good quality and supply of wine in high quality restaurants. Thus, the object of the compliment is the companies engaged in winemaking. For readers, the fact that first of all the company appreciates the quality of its products is very important. We can say that, in this case, the author creates a message to buy wine of Georgian production.

The following example shows how the stylistic technique of irony is used to implement the compliment tactic.

A man who "wasted years" trying to sculpt his body has become an Instagram influencer on body positivity (BBC Business, 2020).

In the article, the object of the compliment is a young man who has become an example for many people in the 
social network. The story of a young man is that for many years he tried to lose weight to meet the standards of beauty. However, years later he realised that every person creates himself and there is no certain framework. The author positively assesses the fact that the man found the strength to talk about it and became an inspirer for many people in the social network. The irony is that the author calls the "wasted years" actually became a key moment in a person's life. The compliment with the usage of irony becomes more eye-catching and enhances the pragmatic perception.

We put flattery in the same category as the compliment as they are similar in nature. It is important to the sender of flattery that his interlocutor has positive feelings because it affects whether or not a sender of flattery benefits as a result of communication. The speaker of flattery strives not so much to share his emotional charge, as to cause it in the interlocutor for his own selfish purposes. The intentions of evaluative statements are not limited to the intention to communicate their positive-evaluative opinion about the subject and create a positive emotional background, but they are also characterised, for example, by the desire to regulate the behaviour of the receiver, to establish a contact with him, to observe the communicative ritual, etc. (Malyuga et al., 2019). In our case with researching the articles, the first intention prevails over others.

Some linguists call this tactic can also be called pseudo-positive (Bigunova, 2019). According to her studies, pseudo-positive evaluative speech act of flattery is characterised by the presence of consideration and self-interest in the motivation of the speaker. In this speech act, the addressee and the object of a positive-evaluative statement, as a rule, coincide (the only exception is flattery directed at a person close to the interlocutor). The speech act of flattery has a very direct, explicit form of evaluation and is formulated mainly in the framework of the initiating communicative course. The objects of the speech act of flattery are the appearance of the addressee, his moral and intellectual qualities, skills, achievements, and actions (Cavazza, 2017).

Despite the fact that many scientists distinguish this tactic among the tactics used to implement the strategy of positive assessment, it is necessary to note that flattery is more peculiar to oral discourse.

\subsection{The Tactic of Self-Identification}

The tactic of self-identification is aimed at demonstrating proximity, community, unanimity with the communicative partner. This tactic expresses the consent, the development of the theme, the joining to the opinion of the communicative partner, summarising, creation of the concept "we", the community, demonstrating a willingness to cooperate, intimacy (reduction of communication and physical distance), comfort, call for joint action (Lapresta-Rey et al., 2019).

The assessment tactic of self-identification can also be considered in the context of rapprochement, i.e., the author's desire to get closer to the audience, to show that his opinion is identical. However, this tactic can be seen as a desire to get closer to a positive position on a particular issue. In that case, the participant of communication (the author) gives the described object positive characteristics and seeks "to be self-identified" with it.

The following article describes the attempt of Great Britain and Japan to establish trade relations.

Ms Truss said that she hopes to build on the existing pact between Tokyo and Brussels: "We aim to strike a comprehensive free trade agreement that goes further than the deal previously agreed with the EU, setting ambitious standards in areas such as digital trade and services."

"This deal will provide more opportunities for businesses and individuals across every region and nation of the UK and help boost our economies following the unprecedented economic challenges posed by coronavirus," Ms Truss added (BBC Business, 2020).

From the point of view of linguosynergetics, the analysed passage is an open self-regulating non-linear system of meanings. Propositions are linked by logical-semantic and pragma-semantic links (general and specific order parameters). The first part of the article is devoted to the problems that countries may face after the UK leaves the EU. We can say that the system of meanings is in the initial state of relative order.

Judgmental discourse is built around the formation of a positive image of relations between the two countries (functional attractor). The property of openness lies in the fact that the system of meanings is open to outside influence and changes in it occur under such influence. The system of meanings is subject to fluctuations and reaches the point of bifurcation - the choice of the path of development to destruction or a new order. The logical-semantic operator "switching" (from the topic of the complexity of relations to the topic of finding ways to reach an agreement) marks the transition of the semantic system to a new state: syntactic parallelism is applied (Discussions with Brussels... Discussions with Japan). 
The movement towards a new order is provided by the "merging of energies" of different-level speech means. The British side stresses new opportunities in the new status (ambitious standards, boost our economies, goes further than the deal previously agreed with the EU, more opportunities). For this, lexemes with positive semantics and comparative adjectives are used.

After the words of the representatives of the parties and some statistics, the author again describes the benefits that the conclusion of the agreement will bring. Such argumentation reinforces the new state of the system of meanings.

How does the communicative situation (external environment) affect the evolution of the system of meanings of this passage? Analysing the article as a whole, we see that the author ranks Japan among the most influential partners (the fourth-largest non-EU trading partner). The article is dominated by the words of the British side about the benefits of the new agreement and nothing is said about the position of Japan. Previous similar negotiations with the EU are called difficult. Thus, we can conclude that the position of the author of the article is very appropriate and will contribute to the development of bilateral business relations. Discourse is not divorced from reality, does not exist in isolation, it is conditioned and connected with the environment of modern business life, in this sense, the system of discourse meanings is open.

The following excerpt provides an example of the self-identification tactic implemented by the imperative mood.

Don't kid yourself you're getting business class seats on the cheap (The Guardian, 2020).

With the help of imperative mood and phrase more typical for colloquial speech, the author assures readers that the place and level of service in business class on the plane they can get at a very reasonable cost. In this case, it should be noted that the author identifies himself not with the audience, but with a positive situation for the audience. Thus, he seems to speak on behalf of airlines offering business economy class and encourages readers to buy tickets there. As a result of the pragmatic impact, readers can trust the author and follow his recommendations.

From the grammatical point of view, it is necessary to consider an example of the implementation of this tactic with the help of comparative adjectives.

Women are getting on to corporate boards at greater speed, and in greater numbers (The Economist, 2020).

This example does not express the praise of a certain trend, but with the help of a comparative degree of adjectives with a positive semantic meaning, the author shows that he is in solidarity with the situation and has a positive attitude to the fact that in recent years in the corporate boards can be seen not only men but also women and their amount in high positions is growing. Thus, this article can be seen as a veiled impulse for women, in order to show that the modern world provides them with all the opportunities for career development.

In the following example, we can see the implementation of the tactic of self-identification based on metaphor and oppositeness.

The glass ceiling in the corporate world is not broken, but it is starting to crack (The Economist, 2020).

In this situation, the author describes the change for the better, based on a metaphor with a glass ceiling. The article is devoted to the fact that women in the modern world have more opportunities to take a leadership position. Thus, the author displays the realisation of this possibility with a crack of the glass ceiling. However, he notes that today this problem is not completely solved. Here we see the opposition: not broken, but cracked. In this case, the self-identification of the author again refers to the desire to show his closeness to the positive trends. He makes it clear to the reader that the world is changing, thereby instils confidence in women that they can take leadership positions on an equal footing with men.

So, we can observe the variety of lexico-grammar, semantic, stylistic means which together, in their accumulative effect, realise the pragmatic potential of discourse.

\section{Conclusions}

The present study fills the gap in the field of functional linguosynergetics of business discourse. The authors have introduced the term "judgmental discourse" and for the first time classified the most common tactics of positive assessment. The study opens up prospects for further exploration of negative and neutral assessment in discourse. Moreover, we have described the main pragma-semantic features of assessment in printed business discourse. These are systemacy, openness, self-organisation, non-linearity, heterogeneity on all levels.

As positive assessment was under investigation, we have described the process of judgmental discourse evolution. We have revealed that assessment is a component of linguosynergetic system of discourse and is 
functioning according to the laws of self-organisation.

The study has stressed the flexible nature of the discourse system and described several frequent discursive tactics corresponding to positive assessment strategies. It turned out that praise, compliment, flattery, and self-identification constitute the largest part of positive assessment tactics.

Our research has shown that judgmental discourse has many points of contact with business media discourse. A systematic view of the development of its pragma-semantic space made one can understand in what ways it is possible to enhance speech impact. Positive judgment has a significant potential for forming the reader's picture of the world, while it does not always have to be straightforward, often hidden techniques or a set of techniques uncharacteristic of business speech are used. Such phenomena become a source of semantic augmentations and emergent properties manifested by the discourse system, helping it to move towards the communicative goal-formation of a positive image.

\section{Acknowledgments}

The publication has been prepared with the support of the RUDN University Program (The program aimed to boost the competitiveness of Peoples' Friendship University of Russia (RUDN University) among the world's leading research and education centers in 2016-2020) (recipient A. V. Radyuk, scientific research).

\section{References}

Bankovskaya, N. A. (2007). Direct assessment as an expression of the opinion of a journalist in the modern press in Russia and Germany. In M. A. Kormilitsyna \& O. B. Sirotinina (Eds.), Issues of speech communication (Vol. 7, pp. 105-111). Saratov: Saratov University Publishing house.

Bargiela-Chiappini, Fr., Nickerson, C., \& Planken, B. (2007). Business Discourse. New York: Palgrave Macmillan. https://doi.org/10.1057/9780230627710

Bigunova, N. (2019). Cognitive pragmatic regularities in communicative manifestation of positive evaluation. Legeartis. Language Yesterday, Today, Tomorrow, 4(1), 2-46.

Cavazza, N. (2017). The Tone Dilemma: Comparing the Effects of Flattery and Verbal Aggression in a Political Speech. Journal of Language and Social Psychology, 36(5), 585-598. https://doi.org/10.1177/0261927X17698186

Chan, A. C. K., \& Du-Babcock, B. (2019). Leadership in action: an analysis of leadership behaviour in intercultural business meetings. Language and Intercultural Communication, 19(2), 201-216. https://doi.org/10.1080/14708477.2018.1508291

Chatti, S. (2020). Seasonal metaphors in Arab journalistic discourse. Metaphor and the Social World, 10(1), 22-44. https://doi.org/10.1075/msw.18020.cha

Dijk, T. A. v. (1983). Cognitive and conversational strategies in the expression of ethnic prejudice. Text, 3-4, 375-404. https://doi.org/10.1515/text.1.1983.3.4.375

Dijk, T. A. v. (2000). Language, Knowledge, Communication. Blagoveshensk: BGK im. I.A.Baudouin de Courtenay.

Frana, I., \& Rawlins, K. (2019). Attitudes in discourse: Italian polar questions and the particle mica. Semantics \& Pragmatics, 12 . https://doi.org/10.3765/sp.12.16

Frolova, I. V. (2015). Subject and object of assessment within the framework of assessment strategies in an analytical article (based on the material of the British and Russian high-quality press). MGOU Bulletin (Series: Linguistics), 2, 93-100.

Gabidullina, A. R. (2013). Estimated statements in pedagogical discourse. RUDN Bulletin (Series: Theory of language. Semiotics. Semantics), 3, 36-45.

Georgakopoulou, A. (2002). Narrative and identity management: Discourse and social identities in a tale of tomorrow. Research on Language and Social Interaction, 35(4), 427-451. https://doi.org/10.1207/S15327973RLSI3504_2

Hamiti, V., \& Sadiku, M. (2020). Perception and Evaluation of the Balkans as a Powder Keg in the German-language Press Discourse. Studien Zur Deutschen Sprache und Literatur-Alman DiliVeEdebiyati Dergisi, 43, 39-67. https://doi.org/10.26650/sds12019-0020

Issers, O. S. (2012). Communicative strategies and tactics of Russian speech. Moscow: Publishing house LKI.

Ivin, A. A. (2015). Foundations of the logic of estimates. Retrieved July 22, 2020, from 
https://www.directmedia.ru/book_435526_osnovaniya_logiki_otsenok/

Jenkins, S. (2019). Would you like your Brexit vanilla or Marmite? It's time to choose. Retrieved July 20, 2020, from https://www.theguardian.com/commentisfree/2019/mar/09/vanilla-brexit-marmite-tories-labour

Jiang, J., \& Zhang, J. (2020). Implicit evaluation in academic discourse: A systemic functional perspective. Australian Journal of Linguistics, 40(2), 161-180. https://doi.org/10.1080/07268602.2020.1734774

Lapresta-Rey, C., Huguet, Á., Petreñas, C., \& Ianos, A. (2019). Self-identifications of youth in Catalonia: a linguistic acculturation theory approach. Journal of Multilingual and Multicultural Development. https://doi.org/10.1080/01434632.2019.1656219

Macagno, F., \& Botelho, W. S. P. R. (2020). Reconstructing Multimodal Arguments in Advertisements: Combining Pragmatics and Argumentation Theory. Argumentation. https://doi.org/10.1007/s10503-020-09525-z

Mak, B. (2020). Doing business and constructing identities through small talk in workplace instant messaging. Pragmatics and Society, 10, 559-583. https://doi.org/10.1075/ps.16064.mak

Malyuga, E., Maksimova, D., \& Ivanova, M. (2019). Cognitive and discoursive features of speech etiquette in corporate communication. International Journal of English Linguistics, 9(3), 310-318. https://doi.org/10.5539/ijel.v9n3p310

Malyuga, E., Shvets, A., \& Tikhomirov, I. (2016). Computer-based analysis of business communication language (pp. 229-232). In SAI Computing Conference 2016. July 13-15, 2016. London, UK. https://doi.org/10.1109/SAI.2016.7555987

Malyuga, E. N., \& Orlova, S. N. (2016). The art of business interviewing in ESP training (pp. 7231-7235). In EDULEARN16 Proceedings. Spain, Barcelona. https://doi.org/10.21125/edulearn.2016.0574

Partington, A. (2007). Irony and reversal of evaluation. Journal of Pragmatics, 39(9), 1547-1569. https://doi.org/10.1016/j.pragma.2007.04.009

Ponomarenko, E. V. (2016). Functional properties of English discourse in terms of linguosynergetics (Book 1, vol. 3, pp. 355-362). In 3rd International Multidisciplinary Scientific Conference on Social Sciences and Arts SGEM 2016 Proceedings. Bulgaria, Albena.

Ponomarenko, E. V. (2018). The notion of functional synergism in linguistics (Book 1, vol. 5, pp. 501-508). In 5th International Multidisciplinary Scientific Conference on Social Sciences and Arts SGEM 2018 Proceedings. Austria, Vienna. https://doi.org/10.5593/sgemsocial2018H/31/S10.063

Ponomarenko, E. V., Magirovskaya, O. V., \& Orlova, S. N. (2020). Introduction: Professional discourse in the focus of functional linguistics. In E. Malyuga (Ed.), Functional Approach to Professional Discourse Exploration in Linguistics (pp. 1-20). Springer, Singapore. https://doi.org/10.1007/978-981-32-9103-4_1

Radyuk, A. V. (2013). Functional-pragmatic properties of cooperative speech strategies and tactics in English business discourse (Candidate thesis abstract). Moscow State Institute for International Relations, Moscow, Russia.

Shiryaeva, T. A., \& Avsharov, A. G. (2018). Sociocognitive modeling as a methodological basis for studying a business discourse. Issues of Cognitive Linguistics, 1(54), 94-102. https://doi.org/10.20916/1812-3228-2018-1-94-102

Smale, W. (2020). The eyewear designer for the stars. Retrieved July 18, 2020, from https://www.bbc.com/news/business-46916809

The Guardian. (2020). The Guardian view on the EU budget: hitting the wrong notes in Hamilton. Retrieved July 24, 2020, from https://www.theguardian.com/commentisfree/2020/jul/24/the-guardian-view-on-the-eu-budget-hitting-the-w rong-notes-in-hamilton

Volf, E. M. (2006). Functional semantics of evaluation. Moscow: KomKniga.

\section{Copyrights}

Copyright for this article is retained by the author, with first publication rights granted to the journal.

This is an open-access article distributed under the terms and conditions of the Creative Commons Attribution license (http://creativecommons.org/licenses/by/4.0/). 